\title{
ROLE OF GEOLOGY IN PROJECT DEVELOPMENT
}

\author{
Jaroslav Jakubec ${ }^{1}$ \\ ${ }^{I}$ SRK Consulting, Canada
}

\section{INTRODUCTION}

For a mining operation to be successful, it is important to bring fundamental and applied science together. In other words to educate a mining engineer on one end about the importance of geology, mineralogy and petrography and how he can benefit from data collected during the exploration and pre-exploration stage but also educate geological scientists about the project development from the exploration stage through mine design and operation to mine closure.

It is not uncommon to discover significant data gaps during the final feasibility stage or even during the mine development stage. In many cases such gaps in our understanding of nature of the mineral deposit result in development of delays and cost overruns. Such "surprises" could be avoided if exploration programs integrated some of the mining and geotechnical aspects into their investigation. This does not necessarily translate into a significant inflation of an already stretched exploration budget, if it is done sensibly. However, it requires both parties - mining engineers and geologists - to understand the complete process of a project's development.

This paper illustrates the importance of geology in the diamond mine design and development.

\section{PROJECT DEVELOPMENT}

As soon as the resource (kimberlite pipe) is approximately delineated to a certain depth, and the first indications of values per tonne of rock are available, the question arises "How much will it cost to convert the resource into a marketable product". The feasibility progression process starts and professions other than geologists are (should be) invited to the "table".

Typically the process will have the following steps:

- Conceptual

- Scoping

- Pre-feasibility

- Final feasibility
Mining method selection starts relatively early in the project development and the scramble for input data begins. The choice, design and operation of mining methods are fundamentally dependent on:

- Ore body size and geometry

- Rock mass competency

- Grade distribution

- Desired production rates

- Constraints such as permafrost and lake above

Once the mining method is selected, a conceptual mine design is undertaken and all constrains should be considered. Typical mine design constrains are illustrated in Figure 1 below.

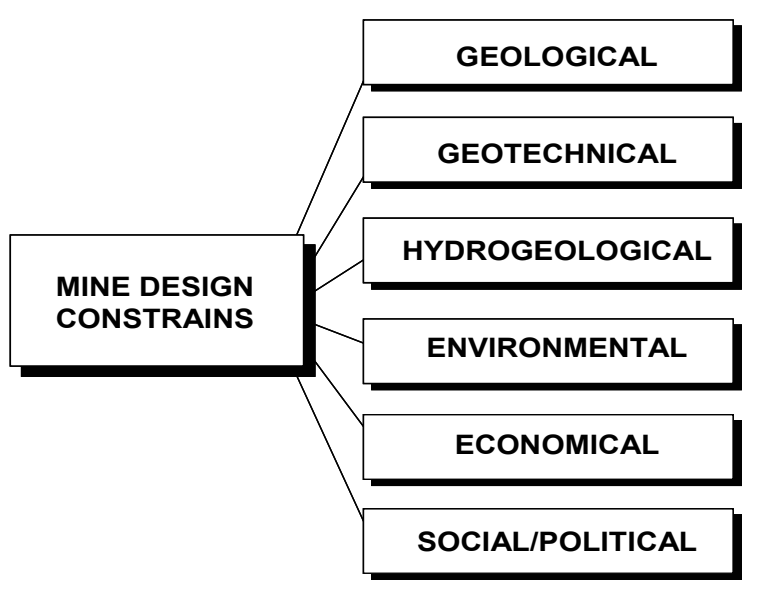

Figure 1: Typical mine design constrains

As illustrated above, geological information is required throughout the project development process. However, the required geological data should not be limited to the resource model (kimberlite pipe or dyke), and should also include the country rock as well.

Often, at the end of the exploration drilling program very little is known about the country rock geology or pipe contact zones even though most of the drillholes were collared or terminated in the country rocks. Country rock information is sketchy, core is "buried" somewhere under the snow and core photographs are not available. It is interesting to note that a set of good core photographs could provide sufficient geotechnical information for the conceptual stage design. 


\section{GEOLOGY CONTEXT}

As illustrated above the geology is fundamental to every stage of the project development process. In the context of the kimberlite mine design three aspects of the geology that could be most important are:

- Regional structural geology

- Kimberlite pipe geology

- Country rock geology

\section{REGIONAL STRUCTURAL GEOLOGY}

Applied structural geology, in most mineral systems, is about understanding pathways. 'Pathways' include, the crustal scale plumbing systems that could facilitate the emplacement of kimberlitic magmas, as well as, the pipe scale fault/fracture networks that control syn-/postemplacement alteration and present-day groundwater flow. Understanding these pathways can therefore have a profound impact on the effectiveness and success of diamond projects at all stages, from exploration, through mine design and mining, to mine closure.

Today's common diamond exploration tools consist primarily of airborne geophysics and quaternary geology (soil sampling). Both techniques used together or in isolation, have in many cases proven to be highly successful means of locating kimberlite pipes. However, in cases where kimberlites have no distinct magnetic signature, and/or lack a traceable dispersion train, an understanding of the crustal architecture and its structural-kinematic evolution, can provide valuable insights to the kimberlite vectoring process. Using existing aeromagnetic data, crustal scale geology and tectonic history of a given area, structural analysis can help identify favourable sites for pipe emplacement.

Integration of detailed structural analysis with on-going geological and geotechnical studies, at the mine scale, can potentially assist in the definition of geometry of the kimberlite intrusive, as well as, the geometry and distribution of its internal facies. This approach can provide obvious benefits to geotechnical domain modeling, and could also play a major role in the definition of the contained and mineable reserves.

Example of enhanced aeromagnetic data visualization revealing internal structures in the kimberlite pipe is illustrated in Figure 2.

Effective management of ground stability and groundwater are two of the most critical elements that underpin the success of any mining operation. Structural analysis and understanding of faults and fracture systems outside, and within, the kimberlite can also help with the early prediction of zones of instability and groundwater risk. Groundwater risks include not only the immediate impediments to development progress, but also the progressive strength degradation, over time, through weathering of groundwater pathways. Structural geology can also, therefore, make a positive contribution to the early stages of mine design, mine planning and mine safety, and its application to groundwater studies further extends its relevance to mine closure and remediation.

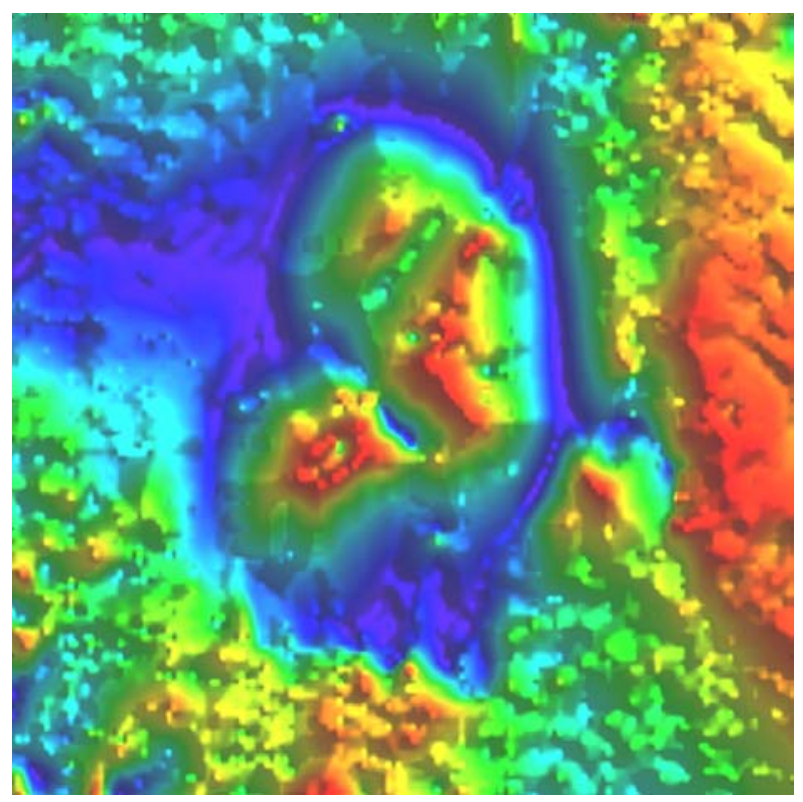

Figure 2: Enhanced processing of the aeromagnetic data reveals structural patterns transecting the kimberlite pipe

The maximum benefit of structural analysis is realized when it is introduced to the project at the earliest possible stages, and carried through the life of the project, with continuity maintained between its different applications to each phase of development.

\section{KIMBERLITE PIPE GEOLOGY}

Three main aspects of kimberlite pipe geology that have direct impact on the mining method selection and design are:

- Kimberlite pipe emplacement model

- Kimberlite pipe geology model

- Kimberlite petrology/mineralogy 


\section{Kimberlite pipe emplacement model}

This is one of the fundamental studies that help to understand the kimberlite pipe geology. Although the importance of the pipe emplacement model is commonly recognized in the resource geology its importance to the mine design is not always appreciated by the mining engineers. The pipe emplacement mechanism could influence the following:

- Pipe size and geometry

- Internal structures and rock type contacts

- Kimberlite rock mass competency

- Extent and character of the pipe contact zones

The parameters mentioned above could directly influence pit wall stability (thus striping ratio), underground mining method selection, dilution, treatment plant process, dewatering strategy etc.

Poor quality contact zones often create mining difficulties in both open pit and underground operations. An example of a highly jointed external contact zone is illustrated in Figure 3.

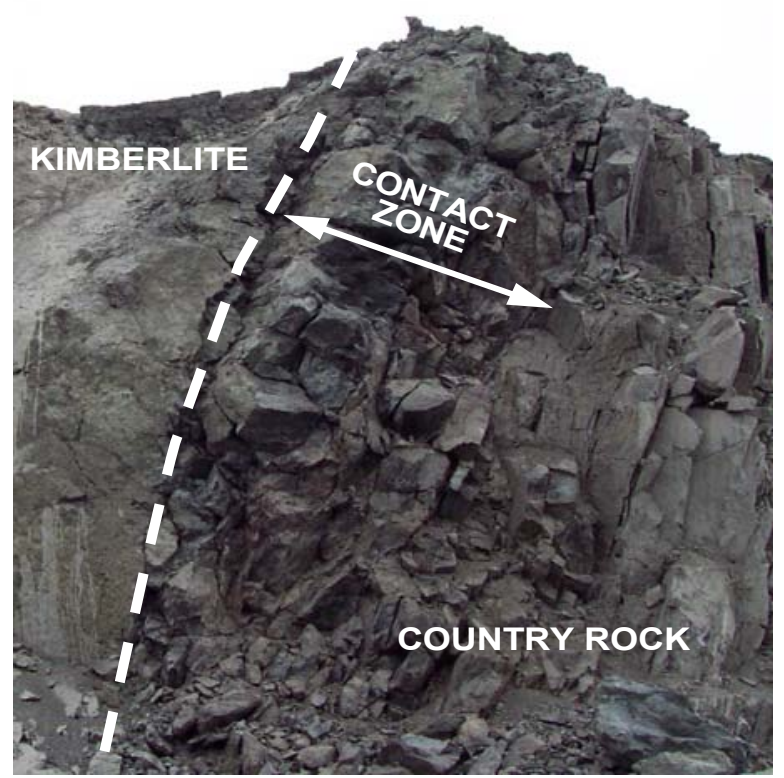

Figure 3: Example of well developed external contact zones outside the kimberlite pipe.

\section{Kimberlite pipe geology model}

Understanding the internal geology of the pipe mainly includes the geometry and character of individual phases and facies, and the orientation and character of internal structures that transect the rock mass. For any mining method it is important to know "where the less and where the more competent rocks are located". On the other hand the detailed facies studies may not be important for the resource and mine design if the rock types have similar physical properties and diamond content.

The pipe geology model is typically used as a base for the geotechnical domain model, see example in Figure 4.

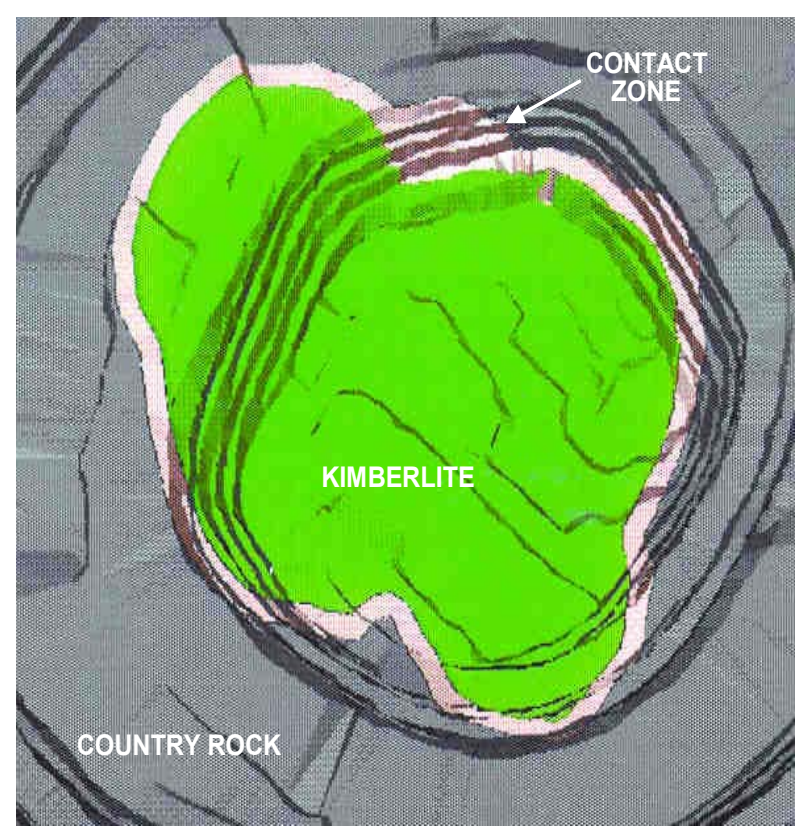

Figure 4: Example of simple pipe domain model. The area represents poor quality pipe contact zone.

\section{Kimberlite petrology and mineralogy}

Forming a good understanding of the kimberlite petrology and mineralogy could be crucial to the treatability (namely diamond damage and liberation), but also to the pit wall (see Figure 5) and underground excavation stability, support design, mine safety (mudrush risk assessment) and mine dewatering.

The most important aspect of kimberlite mineralogy influencing the mine design is clay characterization. This study could provide important clues to the weathering susceptibility of the individual kimberlite rock types and could help delineate geotechnical domains. Relative rates of weathering of different kimberlite rock type could be determined using in situ accelerated weathering tests - see Figure 6 . 


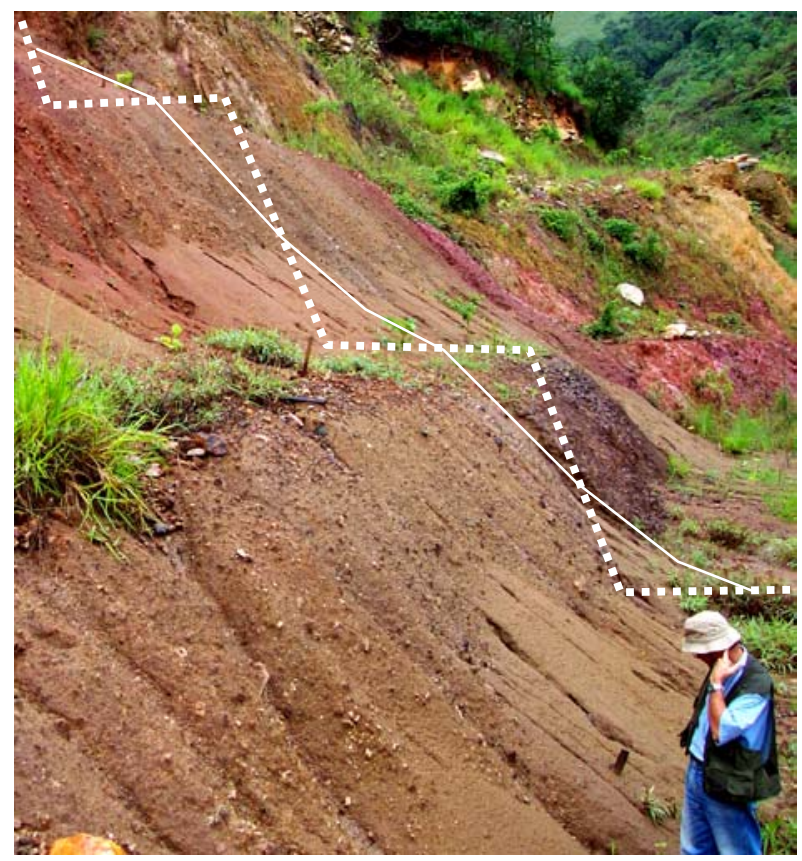

Figure 5: High weathering susceptibility of a clay rich kimberlite cause sever deterioration of the open pit benches. This significantly increases safety risks of the operation and could lead to slope failures.

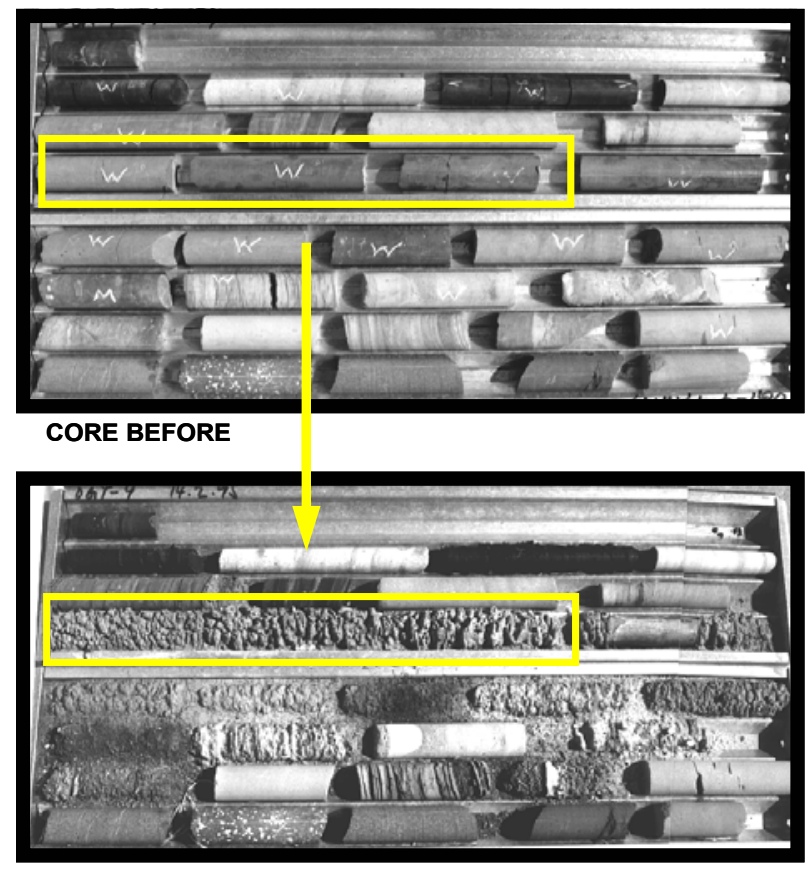

CORE AFTER 3 WETTING AND DRYING CYCLES

Figure 6: Accelerated drill core weathering test reveals variable weathering susceptibility of the individual kimberlite rock types. This simple test could provide a relative comparison of the various units. The rate of deterioration could be calibrated to the clay types and could be used as a predictive mine design tool.

\section{COUNTRY ROCK GEOLOGY}

In the context of mine design the knowledge of country rock geology is at least as important as geology of the kimberlite pipe itself. Pit slopes, underground access development and mining infrastructure are mainly located in the country rocks. In the kimberlite geology the knowledge of country rocks could also be crucial for the pipe emplacement model. The country rock xenoliths could provide important evidence of the volcanic sequence and timing of the pipe formation. Often, during the kimberlite delineation program, holes are terminated as soon as they leave kimberlite. This could (and does) lead to erroneous interpretations of pipe geometries in some cases because the "country rock contact" is only a xenolith.

\section{CONCLUSIONS}

There is no doubt that a better understanding of the geology has a direct impact on the safety and economics of the mining operations. The process of mine design could start right at the beginning of the discovery without necessarily significantly increasing the exploration budget. Even simple issues such as drill core photography during the exploration stage could potentially save hundreds of thousands of dollars on drilling during the subsequent stages of conceptual and pre-feasibility study. Several rock strength estimates performed on the exploration core can provide, at very low cost invaluable information for a "first pass" mine design.

On the other hand it is important to appreciate fundamental geological research and its impact on the increased confidence in mine design. Such studies must not be viewed as cost items but as an investment. However, the investment can only be done efficiently if one understands the whole process, data requirements down the line and risks and uncertainties associated with the project.

Contact: J. Jakubec, SRK Consulting, Suite $800-1066$ West Hastings St, Vancouver, BC, Canada, V8W 3R7, E-mail: jjakubec@,srk.com 